\title{
Aggregation, Validation, and Generalization of Qualitative Data - Methodological and Practical Research Strategies Illustrated by the Research Process of an empirically Based Typology
}

\author{
Daniel Weis $^{1}$ (D) Helmut Willems ${ }^{1}$
}

(C) Springer Science+Business Media New York 2016

\begin{abstract}
The article deals with the question of how aggregated data which allow for generalizable insights can be generated from single-case based qualitative investigations. Thereby, two central challenges of qualitative social research are outlined: First, researchers must ensure that the single-case data can be aggregated and condensed so that new collective structures can be detected. Second, they must apply methods and practices to allow for the generalization of the results beyond the specific study. In the following, we demonstrate how and under what conditions these challenges can be addressed in research practice. To this end, the research process of the construction of an empirically based typology is described. A qualitative study, conducted within the framework of the Luxembourg Youth Report, is used to illustrate this process. Specifically, strategies are presented which increase the likelihood of generalizability or transferability of the results, while also highlighting their limitations.
\end{abstract}

Keywords Qualitative research · Data aggregation · Data validation · Generalization . Single case analysis · Type · Typology · Empirical construction of types and typologies · Theoretical sampling

\section{Contents}

Introduction 1

Methodological Considerations: Objectives, Sampling, and Methodological Design of the Study 3

Aggregating the Data: the Process of Type Construction.......................................

Validation of the Results: Strategies to Increase Generalizability........................13

Daniel Weis

daniel.weis@uni.lu

1 University of Luxembourg, Esch-sur-Alzette, Luxembourg 
General Conclusion: Opportunities and complications in generalization. 18

Compliance with Ethical Standards.

References.

\section{Introduction}

Generalizing research findings, transferring these to other contexts, and interpreting them so that more extensive conclusions can be drawn is a central objective not only of quantitative but of qualitative research as well. "It is not the individual case itself that is of interest, but rather the conclusions and transference that we can derive from the material" (Mayring 2007, p. 18).

In the study described in this article, scientific interest was not primarily focused on the individual cases that were examined but rather on the target population about which the conclusions were to be made. This had already been established in the research context of the study: it was conducted within the framework of the Luxembourg Youth Report 2015 (Willems 2015). The aim of this study was to collect empirical evidence and determine general trends with respect to the youth in the Grand Duchy of Luxembourg. The central theme of the Youth Report was to describe and analyze the transition from adolescence to adulthood. From the perspective of both social science theories as well as from a political and sociological perspective, the report specifically dealt with three areas of transition that characterize transition into adulthood: the transition to the labor market, private transitions (leaving parents home, development of independent forms of living, partnerships, starting a family), and the development of civic engagement. Various scientific methods and data were utilized to describe and analyze these three types of transitions. For this purpose, different methodological approaches were chosen. In addition to using existing statistical data (survey data, administrative data), we also used data that was collected especially for the Youth Report: Both quantitative (standardized surveys of young people who had utilized support services) as well as qualitative studies (expert interviews and interviews with adolescents and young adults) were carried out.

This article focuses on a qualitative survey on 77 adolescents and young adults. The findings should not only provide information about how the 77 selected participants cope with their transition from adolescence to adulthood, it should additionally enable conclusions to be drawn about the course of transitions and coping patterns of young people in Luxembourg in general. However, how can we ensure that the findings identified here are not only relevant for the studied population, but have relevance for the target population thus allowing general conclusions to be made? Unlike quantitative research and statistics, inductive conclusions with broader validity claims cannot be derived from qualitative social research easily. These types of general conclusions are, however, normally not pursued by qualitative, interpretive research measures, because qualitative research follows a different kind of generalization logic. Nevertheless, generalizable conclusions from single cases are possible because it is assumed that general phenomena can also be found in single cases and that the single case is at the same time part of universal structures. Yet certain requirements are necessary to draw such conclusions. 
Therefore, we applied both methodological and practical research strategies during the research process to increase the generalization potential of the findings. This research process is illustrated in this article as follows. First, methodological considerations and objectives of the qualitative study are outlined (Section 2). Second, the process of data aggregation - from the single case to a typology — is described (Section 3). This is, third, followed by a description of the strategies used to foster the validation of our data, which contributes to significantly increasing the probability of generalization (Section 4). The article concludes with a compilation of the opportunities and complications of generalization (Section 5).

\section{Methodological Considerations: Objectives, Sampling, and Methodological Design of the Study}

It is common knowledge that a variety of methodological approaches are available in the social sciences. The selection of the appropriate method and practical research approach must primarily be directed toward the line of questioning and the object under investigation. Our methodological considerations before initiating the actual investigation are outlined below.

\section{Research Focus of the Qualitative Study}

We used various methods to pursue the different research goals (Willems et al. 2015a). In the context of the Luxembourg Youth Report, the quantitative analyses allowed us a more objective view of the transition processes by representing empirical data in frequencies. The analysis of secondary data served to differentially depict the situation of adolescents and young adults according to age, gender, nationality, or social origin, thus allowing the statistical description and analysis of transitions. Specifically, the standardized survey of participants in support services focused on their experiences and appraisals of the services to identify supportive factors and areas for improvement.

The quantitative analyses were complemented by a separate qualitative study. The objective of this was to record the subjective views, experiences, and coping strategies of youths during the transition process. Qualitative assessment was indicated for this purpose, specifically because the advantage that is inherent in "the relatively open format $[\ldots]$ which allows the perspective of the questioned participant to be taken into account" (Flick 2002, p. 117).

The subjective transition experiences and coping strategies of adolescents and young adults during the transition period were empirically collected by means of the qualitative interviews. Here, a dual aim was pursued: First, we focused on understanding each single case and on detecting the diversity among cases - a central feature of qualitative research. By analyzing the single cases, we could trace the different transition courses, which allowed insights into the structure of each individual transition. Subsequently, the single-case data were aggregated to search for patterns and rules that extend beyond the single case and to derive more general findings. In this way, similarities and differences with respect to the transition processes could be identified along with factors that influence these. Grouping the transitions into different types based on the aggregated data is the methodological goal of the evaluation. 


\section{Methodological Aim of the Analysis: Establishing an Empirically Based Typology}

The goal of typology construction in empirical social research is to derive and explain typical patterns and rules from the data (Bohnsack 2003). The term type is understood as a certain combination of features (or categories) and characteristics (or subcategories), by which some groups or subgroups can be distinguished from other groups (Uhlendorff 2010). The methods used to create types are therefore methodologically guided grouping processes that classify a specific object area into a group or type according to one or more characteristics. Typological classification makes it possible to determine and interpret the similarities and differences between groups (Kuckartz 2010a).

Typology-creating procedures are applied where the goal of empirical research does not consist of a test of preformulated statements, but lies in the discovery, description, and systemization of observations in the field (Kelle and Kluge 2010). They aim to "capture complex social realities and contexts in order to better understand and explain them" (Kluge 2000, p. 1). In the search for the typical case, the single case and the standard case can be meaningfully linked together by means of typological methods (Kuckartz 2010a). Therefore, typological methods are located between case-specific methods on the one hand and comparative analysis strategies on the other (Mayring 2002).

At the center of all typological methods is the comparative contrast of the examined cases. This is understood as case comparison and case contrasting, by which the similarities and differences in the single cases are established and different groups are formed that can be very similar with respect to certain subcategories (internal homogeneity) and can be distinguished from other groups (external heterogeneity) (Uhlendorff 2010). In the qualitative study described here, we sought an empirically based typology which compared, systematized, and interpreted the value orientations, perspectives, courses, and coping strategies of adolescents and young adults with respect to their transition (Kelle and Kluge 2010).

The creation of typologies has a long tradition in youth research with the goal of showing the variance between different young people or groups of young people. As part of the Luxembourg Youth Report, the aim was to reduce the variety of adolescent attitudes and actions in the context of transition to a reasonable number and to interpret their similarities and differences. This was meant to demonstrate the diversity and heterogeneity of transitions of young people in Luxembourg. On the other hand, groups of youths should be identified that are characterized by similar transition patterns, attitudes, patterns of action, and coping strategies. Factors influencing the transitions should be derived by comparing the types and their characterizing features, allowing for the identification of typical progression patterns.

\section{Sampling Strategy}

As in quantitative social research, reality should be randomly investigated in qualitative social research as well. Therefore, making a correct and adequate selection of the persons or cases to interview is a key requirement for deriving valid and generalizable results. Precisely because of the relatively small number of cases in qualitative analyses is it very important to carefully select the cases under investigation (Seawright and Gerring 2008) 
In quantitative research, the aspect of representativeness is crucial for the sampling because conclusions for the entire population are to be drawn from the selected sample. For this purpose, random samples are selected which should display the relevant characteristics to the same extent as the population from which they are drawn (Jacob et al. 2013). In qualitative research, however, the key criterion for the selection of the cases is not their statistical representativity, but their theoretical relevance. The sample should representatively reflect the theoretically relevant categories (theoretical representativeness). This requires a conscious decision on the analytical level about what data can be collected from which persons (groups) (Cohen et al. 2007; Flick 2008). Thus, the sample composition is based on theoretical considerations (following the theoretical sampling approach, Glaser and Strauss 1998). The selection criteria is the assumption that the persons to be interviewed could contribute to the exploration of the subject area to be analyzed (Mason 2010).

\section{Importance of the Number of Cases and Theoretical Saturation}

The sample composition of a qualitative study differs from that of a quantitative study not only with respect to aspects of representativeness. Also the number of cases under investigation plays a different role in qualitative studies (Marshall et al. 2013; Sandelowski 1995). A large number of cases is not necessarily an indication of better information because it is not the quantity of information but rather the significance and thus the quality of the information that is relevant, irrespective of the frequency in which it occurs. "[T]he sample size becomes irrelevant as the quality of data is the measurement of its value. This is as a result of an interaction between the interviewer and the participant" (Guest et al. 2006).

All relevant viewpoints and perspectives should be represented in a qualitative sample if possible, although at the same time the sample should not be too large. Otherwise, there is a risk that the sample is overloaded and cluttered with redundant, and thus, unnecessary information (Marshall et al. 2013; Mason 2010; Sandelowski 1995).

Less crucial for adequately surveying a subject area is a large number of cases; much more important is the "theoretical saturation" (Chowdhury 2015; Glaser and Strauss 1998). This is achieved "once a concept is completely defined in its characteristics, conditions, and consequences" (Przyborski and Wohlrab-Sahr 2010, p. 192). Decisive for the theoretical or empirical saturation of the sample is the targeted selection of interviewees according to the theoretical considerations. In the present study, the sample consisted of 77 adolescents and young adults, which constitutes a large sample size for a qualitative study.

\section{Criteria-Based Case Selection}

To achieve a balanced sample distribution and an "appropriate representation" of the target population (Helfferich 2011), interviewees were selected according to predefined criteria. For this purpose we employed empirical, theoretical, and pragmatic considerations.

Target group of the survey were young people between the ages of 15 and 34 years $^{1}$ who were either currently in or who had already completed the transition phase to adulthood.

\footnotetext{
${ }^{1}$ This large age range is attributable to the fact that the transition to working life can extend into the fourth decade of life due to the extended period of education.
} 
In view of its outstanding importance for societal integration, the focus was on the transition to work because this represents the key transition area for young people (Kohli 1985, 1988, 2000). Assuming that this transition can be displayed along a continuum (from unsuccessful to completely successful transition), on the phenomenological level there are an infinite number of possibilities, whereby the individual cases are situated at different locations along this continuum. This spectrum should be covered by the sample. According to the "model of empirically grounded type construction" (Kelle \& Kluge) we therefore defined a priori case groups: Our assumption was, that the endless number of single cases can be grouped into theoretical subgroups which differ in relevant characteristics.

Building on these considerations, the sample was defined via selective sampling by means of criteria-guided selection of cases. This should appropriately reflect the diversity in shaping and mastering the transitions, thus including adolescents and young adults who experienced different progressions and varying success of their transitions. The choice of interviewees aged between 15 and 34 years was therefore based on the following criteria:

- different educational attainment

- proportionate distribution according to gender

- proportionate distribution according to age

- with and without migration background

- variations in employment status ${ }^{2}$

In the search for specific cases we considered both those with minimal and maximal contrast (Helfferich 2011; Kelle and Kluge 2010). Specifically, we searched for comparison cases that were structurally similar (minimal contrast) as well as those with a clear distinction with respect to the comparison criteria (maximal contrast).

However, the composition of the sample has not been determined by our assumptions and criteria but was an iterative process, i.e. the participants have been recruited during the data collection process. This procedure enabled us to utilize the information from the interviews that had already taken place to perform a type of needs analysis which then guided the selection of further interviewees. For example, we recognized during the interview process that we had interviewed several young people facing a problematic transition who got help in support schemes, but rarely young people trying to deal with their transition problems on their own. Consequently we looked particularly for these young people. A continuous documentation of both content and statistical aspects of the sampling procedure allowed us to control the recruiting process and ensured that the sampling distribution corresponded to the theoretically established criteria, so that all relevant perspectives had been represented in the end.

Thus, the requirements for achieving a heterogeneous, composite sampling distribution could be met: The distributions according to age, gender, employment status, educational attainment, and migration background were balanced and in line with our specifications, so that theoretical representativeness was given.

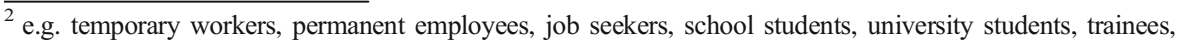
young people participating in an orientation phase, in a governmental support scheme, parental leave, etc.
} 


\section{Selection of the Survey Method}

The instrument we selected for data acquisition was based on Witzel's (1982, 2000) guideline-based problem-centered interview. The problem-centered interview is a theoryguided instrument that focuses on the perspective and the subjective interpretation patterns of the interviewee. It aims for "an unbiased as possible detection of individual actions and subjective perceptions and ways of processing social reality" (Witzel 2000, para. 1), whereby it "understands the respondents as experts of their own orientations and actions" (Witzel 2000, para. 12) and thus involved as competent and useful providers of information in the research process. By combining theory-based assumptions with a fundamental openness to the subjective views of respondents, this method appeared particularly suitable for the investigation of transition experiences. This allowed our theoretical assumptions about transition experiences to be supplemented and aligned with the individual experiences of the participants.

In addition, the problem-centered interviews were supplemented by facets of biographical narrative interviews (Schütze 1983). However, the complete biography was not of interest here but rather certain excerpts including schooling and post-school career as well accompanying factors such as the participant's social environment. Hence, the assessment method used in this study can be described as a guidelinebased problem-centered interview with narrative passages.

The basis for the individual interviews was a self-developed interview guide which included the central topics. The theoretical points of references formed the framework and represented the previous knowledge of the investigation. The interviews were semi-structured, that is, the questions presented to the participants were guidelinebased or situation-based on the course of the discussion (ad hoc questions). The guideline included questions on all three transition areas. The young people who were interviewed were given the opportunity to place the focus of their stories on the area that was most relevant for them. This allowed us to account for the fact that the transition course can be more or less problematic in the different areas. Moreover, additional questions were formulated and posed to the different subgroups (e.g., school students, university students, participants with a migration background, young parents, etc.).

\section{Aggregating the Data: the Process of Type Construction}

After data collection, the 77 interviews were transcribed, analyzed and interpreted by the research team. Initially, evaluation was performed on an individual basis before the data were aggregated in further analyses and ultimately condensed to new structures, that is, the types. The continuous integration of empirical and theoretical steps characterized this approach: On the one hand, only a theory-guided procedure can ensure that the dimensions to be structured by the empirical analysis are relevant for the research question; besides it is hardly possible to proceed without any theoretical assumptions. At the same time, the underlying theoretical conception must be "heuristically useful" (Kelle and Kluge 2010, p. 40), that is, it must be relevant for the material. The whole process of data analysis was hence an inductive-deductive and consequently both a bottom-up and top-down approach. 
The evaluation process, from data preparation to single-case analysis to creation of the typology, consisted of eight phases, and these are shown in Fig. 1 and described below. This is based on Mayring's (2010) practical research suggestions for content analysis as well as Kelle and Kluge's (2010) method of typology construction and Kuckartz's (2010a) typological analysis approach.

\section{Data preparation}

The single cases served as the basis for the analytical process. All interviews were recorded, transcribed, and prepared for subsequent analysis. Data preparation consisted of the consecutive documentation of the interviews as well as content and statistical descriptions of the sample. In accordance with data protection guidelines, the interview data were anonymized following the appropriate anonymization procedures.

For each interview we created an approximate two-page summary of the transition process and its special features. These summaries served as the basis for the analysis in that they enabled a quick overview of the empirical material and furthermore helped to supplement the preliminary theoretically derived category system (see below) from an inductive perspective.

In addition, we created a list of variables to document sociodemographic data and information regarding prior education and career. These data were used to first describe and further develop the included sample (see above) and second, the data served as the basis for forming an initial grouping of the cases.

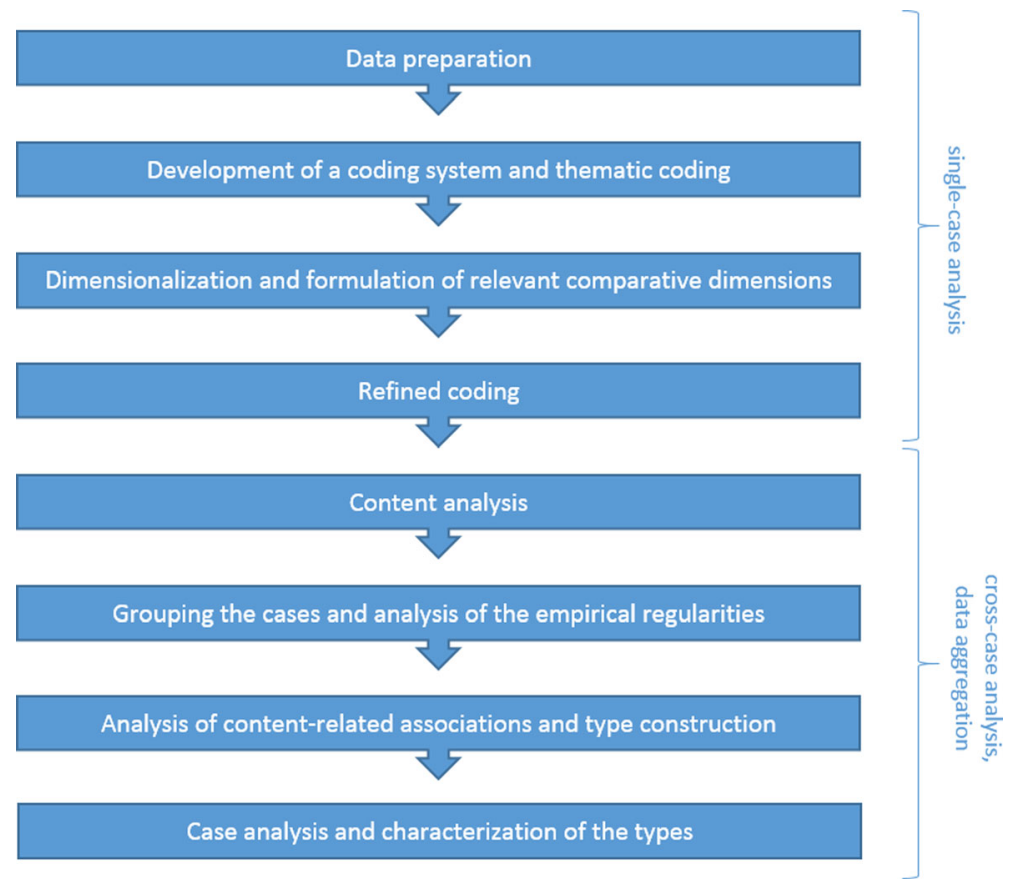

Fig. 1 Stages of data analysis 


\section{Creation of a coding system and thematic coding}

To begin with, we specified the dimensions of the evaluation and developed a category system. This step, although guided by theory, was at the same time open: The categories (codes) were initially based on the interview guideline. They represented the relevant topics that had been theoretically determined beforehand. This preliminary category system was developed inductively through a process of summarizing, clarifying, or differentiating the thematic categories after reviewing the material. A clear definition and delineation of the categories was important in order to ensure that the specific codes could be explicitly assigned to the text passages. The first, broad coding (thematic coding) served the purpose to subdivide the information and to structure and identify key issues and questions. This was performed using the computerized analysis software Atlas.ti.

Figure 2 exemplarily depicts a coding extract from the Atlas.ti program.

\section{Dimensionalization and formulation of relevant comparative dimensions}

Following the initial, broad thematic coding, we sought to dimensionalize and differentiate the original categories. According to the dimensions of transitions to adulthood we wanted to analyze, the issues and characteristics that designate the subsequent typology were defined (Uhlendorff 2010).

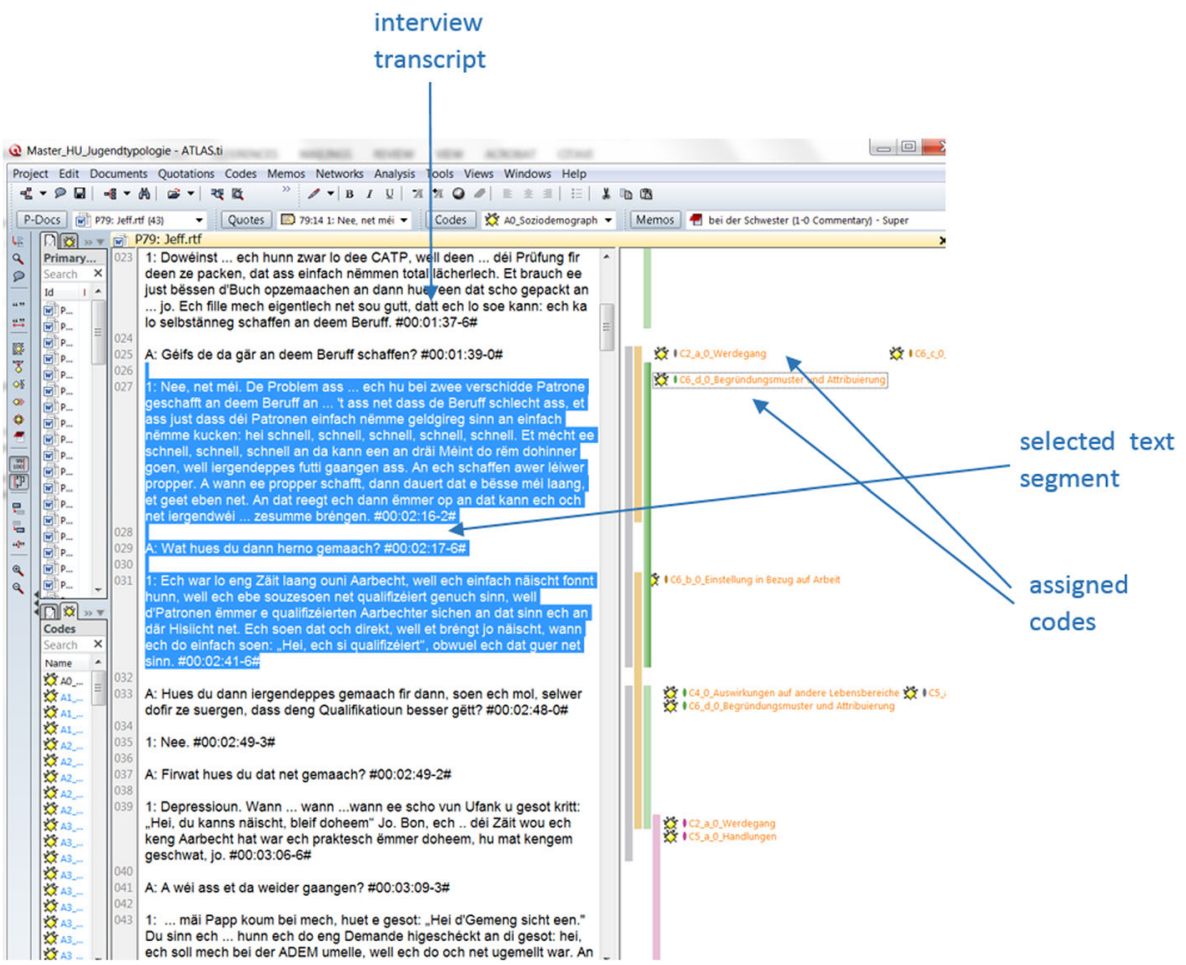

Fig. 2 Coding with Atlas.ti (Extract) 
For each category, comparison dimensions (characteristics) and their varying manifestations have been identified and defined (dimensionalization). These were based first on theories of attitudes and perspectives of youth regarding their transitions that underlie the current study (see, among others, Havighurst 1972; Hurrelmann 2009; Rahn 2005; Reinders 2003). Second, they resulted from the spectrum of answers that we encountered empirically to each code. Thus, the properties as well as their dimensions have been developed both deductive according to our interview guidelines and inductive according to the empirical data material. The characteristics identified in this manner replaced the original categories so that a new, differentiated category system was in place which reflected the heterogeneity and the variance of the single cases (Kelle and Kluge 2010). This division into main and subcategories (codes and subcodes) allowed the hierarchical organization of a category system that was initially linear. Table 1 presents a selection of the comparison dimensions that were identified.

Table 1 Comparison dimensions and characteristic attributes (selection)

\begin{tabular}{|c|c|}
\hline Comparison dimension & Characteristic attributes \\
\hline Decision source & $\begin{array}{l}\text { - own initiative/freely chosen } \\
\text { - externally dictated } \\
\text { - ambiguous/miscellaneous }\end{array}$ \\
\hline Actions & $\begin{array}{l}\text { - own initiative } \\
\text { - other initiative } \\
\text { - resignation/no action } \\
\text { - ambiguous/miscellaneous }\end{array}$ \\
\hline Family support & $\begin{array}{l}\text { - positive/available } \\
\text { - negative/not available } \\
\text { - claimed/desired } \\
\text { - not claimed/not desired }\end{array}$ \\
\hline Self-efficacy & $\begin{array}{l}\text { - fairly high } \\
\text { - fairly low } \\
\text { • ambiguous }\end{array}$ \\
\hline Motivation & $\begin{array}{l}\text { - fairly high } \\
\text { - fairly low } \\
\text { - ambiguous }\end{array}$ \\
\hline Attitude toward work & $\begin{array}{l}\text { - optimistic } \\
\text { - pessimistic } \\
\text { - ambiguous }\end{array}$ \\
\hline Values and motives regarding work & $\begin{array}{l}\text { - rather materialistic } \\
\text { - rather postmaterialistic } \\
\text { - ambiguous/miscellaneous } \\
\text { - no values }\end{array}$ \\
\hline $\begin{array}{l}\text { Patterns of justification } \\
\text { and attribution }\end{array}$ & $\begin{array}{l}\text { - internal/oneself } \\
\text { - external/external factors } \\
\text { - undetermined/ambiguous }\end{array}$ \\
\hline
\end{tabular}




\section{Refined coding}

Using a jointly developed coding guideline and following the category system, we theoretically reflected on and interpreted all materials by assigning the relevant text segments to the defined codes and subcodes (evaluative coding). This was done by analyzing each interview sentence by sentence; the interviews were thus characterized in thematic clusters. We used the program Atlas.ti to perform the coding. Classification was either passage-related or case-related, that is, either individual text segments were classified (e.g., optimistic attitude in terms of the job search) or the entire case (e.g., person has an optimistic outlook on life). The material was then classified by sorting the individual statements into characteristic categories, that is, the cases were assigned attributes. This was a prerequisite for further analysis and for the recognition of associations, similarities, and differences among the cases.

\section{Content analysis}

After the thematic structuring and reduction of the data, we proceeded with the content analysis along the relevant comparison dimensions. Following the single-case analysis outlined above, this step, performed across all cases, served to aggregate the data. Next, by summarizing, paraphrasing, and selecting the material, we further reduced the material code by code thus enhancing its transparency. This enabled us to discover patterns and associations both within and between the codes.

\section{Grouping the cases and analysis of the empirical regularities}

After coding was completed, the single cases were compared with respect to their properties and characteristics in terms of factors such as family resources, migration background, educational attainment, and employment status. This allowed us to search for similarities and differences between the single cases. Thus, they could be assigned to preliminary groups representing the later types that were subsequently analyzed in terms of empirical regularities.

The basis of typology creation is the definition of a so-called attribute space because typologies are based on different features, and types are characterized according to their specific characteristics. Thus, a type is understood as a combination of specific attributes. Each case can be located in this attribute space. The concept of attribute space allows a comprehensive view of the theoretically possible combinations of characteristics. To visualize the possible combinations, we created an Excel-based data file containing all single cases and their characteristics. The sorting function rapidly grouped the cases according to all possible attributes thus enabling us to identify unusual combinations of characteristics. Figure 3 illustrates the visual support feature.

In this example, the cases are grouped according to the dimension "employment status" (circled in red). At first glance, the differences in educational attainment reported in the next column to the right, "degree obtained," are obvious. Most of the employed participants, with a green-highlighted background in this category (i.e., employment status), have university degrees or university entrance qualifications, and the unemployed cases (highlighted in red) have either middle-level or no school qualifications. The cases highlighted in yellow indicate persons who are participating 


\begin{tabular}{|c|c|c|c|c|c|c|c|c|c|c|c|c|}
\hline Name & Alter : & Migr. $\quad+$ & Ery.status -1 & Abschluss & Famstr $=$ & Fambez ${ }^{-}$ & Werdegang : & Ber. Erf. & Entscheid. & Handlung - & Werte & Attrib. - \\
\hline Eva & $23-26$ & Ja & eqwerbstätig & Hochschul. & + & + & smooth & + & eigen & eigen & mat. & intern \\
\hline Joana & $27-30$ & $J a$ & fwerbstätg & Hochschul. & + & + & smooth & + & eigen & eigen & post. & intern \\
\hline Pierre & $23-26$ & Nein & frwerbstätif & Abitur & + & + & alternative & + & eigen & eigen & post. & $?$ \\
\hline Richard & $27-30$ & Ja & erwerbstätid & Hochschul. & + & + & smooth & + & eigen & eigen & mat. & intern \\
\hline Sophia & $27-30$ & Nein & erwerbstätig & Hochschul. & + & + & smooth & + & eigen & eigen & post. & intern \\
\hline Gilles & $27-30$ & Nein & erwerbstätig & Abitur & + & + & alternative & + & ambivalent & eigen & post. & intern \\
\hline Jos & $23-26$ & Nein & erwerbstätig & Abitur & + & + & inst. repaired & + & eigen & eigen & $\operatorname{mix}$ & extern \\
\hline André & $23-26$ & Nein & erwerbstätig & DAP/CATP & - & + & alternative & + & eigen & eigen & $\operatorname{mix}$ & intern \\
\hline Nadine & $27-30$ & Nein & Maßnahme & kein & 1- & ambivalent & t downward & - & eigen & $?$ & post. & extern \\
\hline Chiara & $15-18$ & Ja & Maßnahme & DAP/CATP & - & ambivalent & t downward & ambivalent & t ambivalent & ambivalent & mat. & extern \\
\hline Jeff & $27-30$ & Nein & Maßnahme & DAP/CATP & - & + & downward & - & fremd & fremd & keine & intern \\
\hline Caroline & $27-30$ & Nein & Maßnahme & Hochschul. & + & + & alternative & + & eigen & eigen & post. & intern \\
\hline Danielle & $27-30$ & $\mathrm{Ja}$ & Maßnahme & Hochschul. & - & + & alternative & + & eigen & eigen & post. & intern \\
\hline Alessandro & $19-22$ & Ja & nicht erw. & DAP/CATP & + & ambivalent & t downward & - & eigen & eigen & mat. & extern \\
\hline Jeremy & $19-22$ & Nein & nicht erw. & kein & - & + & downward & - & ambivalent & fremd & mat. & teils teils \\
\hline Madeleine & $27-30$ & Ja & hicht erw. & kein & - & ambivalent & t inst. rep. & - & fremd & fremd & mat. & extern \\
\hline Patricia & $27-30$ & Ja & ficht erw. & kein & + & + & inst. rep. & - & fremd & eigen & post. & extern \\
\hline Karin & $23-26$ & Nein & njcht erw. & Hochschul. & - & + & inst. rep. & - & eigen & eigen & $\operatorname{mix}$ & teils teils \\
\hline Rene & $19-22$ & Nein & nitht erw. & DAP/CATP & + & + & inst. rep. & - & eigen & eigen & mat. & extern \\
\hline Jerry & $23-26$ & $\mathrm{Ja}$ & & $\mathrm{CCP}$ & + & + & inst. rep. & - & fremd & fremd & mat. & extern \\
\hline
\end{tabular}

Fig. 3 Grouping the cases

in a government-supported labor market integration program; here, all types of educational attainment levels are represented from no school qualification to university degree. Although the associations between employment status and educational attainment held few surprises, other groupings and combinations of characteristics allowed associations and regularities to be uncovered that were not directly apparent.

The groups that became apparent due to this quantification represent the first, "broad" types with recognizable content homogeneity and mutual outward boundaries. The next step consisted of a reduction of the groups. To reduce the number of possible types, the attribute space was gradually reduced, which in turn is characteristic of an empirical typology: As not all the attributes and theoretically possible combinations of attributes can be described and examined, a reduction to some central dimensions must be accomplished. Generating types always implies reducing the tangible diversity in the real world in order for this to be represented by only a few relevant types. The decision for a certain number of types was "a balancing act between the necessary systemization and summary on the one hand and the analytically advisable differentiation on the other hand (Kuckartz 2010a, p. 561).

\section{Analysis of content-related associations and type formation}

Whereas the steps taken so far were more descriptive and primarily for structuring the data, the next two steps aimed to interpret the findings. Since the aspired typology should not only provide a description, but rather explanations of the transition profiles identified in the previous step, we now had to analyze the relationships, combinations, and associations between the characteristics more closely. Cases with identical or similar combinations of attributes that were grouped together in the previous step had to be more closely compared with each other to examine the internal homogeneity of the groups. The groups, in turn, were compared with each other to examine their external heterogeneity in order to determine whether the constructs were able to discriminate from each other adequately.

Thus, the cases of each group were compared according to their comparison dimensions and attribute manifestations. Thereby, we examined the question of whether the 
cases share similarities or are related to each other in certain ways (internal homogeneity). The similarities and differences between the groups were abstracted in order to compress them into types. The cases assigned to a certain type are not necessarily identical in terms of all their characteristic attributes (polythetic types; Kuckartz 2010b, p. 105)

\section{Case analysis and characterization of the types}

The results of the analysis indicated four types of transition and coping patterns: direct transition, alternative transition, transition requiring support, and failed transition (Willems et al. 2015b). These types classified the transitions of adolescents and young adults in Luxembourg and illustrated the diverse paths of different groups with specific attributes.

This typology presents a framework in which the individual cases can be classified and interpreted: In this way, the individual cases can be aggregated, abstracted, and summarized to the new structures, that is, the types. The final analysis step included the comprehensive characterization and illustration of these types. In-depth interpretation of the cases allowed us to identify and clarify associations with reference to the single cases. Thus, the theoretical constructs - the types - were both clear and comprehensible. This step was based on the combinations of attributes and contexts with reference to the underlying theoretical and conceptual perspectives.

Kelle and Kluge (2010) suggest creating portraits for the further explication and illustration of the relations between the individual types. Specifically, one or more prototypes (i.e., from the real cases) are selected that represent the group very well. Typical or particularly illustrative cases are thus exemplified and representative of all cases of a type. In the Youth Report, however, this form of illustration was omitted due to lack of space.

\section{Validation of the Results: Strategies to Increase Generalizability}

The validity claim of empirical findings depends primarily on the quality of the collected data, and this can be assessed based on quality criteria. In quantitative research, the so-called classical quality criteria of objectivity, validity, and reliability have been established as measures for determining the quality of data and the robustness of results. However, their transfer to qualitative methods is not easily possible and meaningful, because qualitative methods follow their own methodological and epistemological traditions, with theories and assumptions that clearly differ from those of quantitative research approaches (Mruck and Mey 2000; Steinke 2008). Nevertheless, qualitative research must be subject to a critical evaluation and review based on objective criteria. This can be based on the established quantitative research criteria, but it must, at the same time, take the specificities of qualitative research into account (Reichertz 2000; Steinke 2007).

In literature, there are different approaches concerning criteria of validity in qualitative research. Specific criteria for qualitative research - sometimes called "alternative criteria" in contrast to the criteria established in quantitative research - have certain weaknesses. For this reason, several authors call for an adaptation of the established criteria to qualitative research. We follow this proposal and argue with these "adapted criteria of validity": objectivity, reliability, internal validity, external validity (according to Wrona 2006). 
The claim of a critical evaluation and review based on objective criteria was taken into account in our study. Throughout the entire research process-from the methodological design of the study and data collection to data analysis and interpretation-methodological and practical research strategies were utilized to ensure the quality of the data and to validate the results, thereby increasing the chances of deriving generalizable conclusions about the findings. The most important strategies are outlined below.

\section{Objectivity and Reliability: Intersubjective Verification of the Procedure}

An important criterion for determining the quality of research is the intersubjective verifiability of the research process, which is also known as "procedural reliability" (Wrona 2006). Reliability refers to consistency or accuracy, and in quantitative research this criterion implies that the same results will arise from repeated use of a method. In a qualitative assessment situation such as an interview, which represents a context- and time-dependent situative (and not arbitrarily repeatable) event, this is not intended. However, the reliability, and hence also the verifiability and transparency, can and should be ensured by a rule-guided approach. This is an important prerequisite for third-party evaluation of the research.

Despite the inherent subjectivity of qualitative research, emphasis was placed on making the data collection as well as the data analysis and interpretation of results transparent and intersubjectively verifiable. Our extensive documentation and explication of the methodological approach contributed to this. Throughout the data collection we also minimized subjectivity e.g. by the fact that the interviews were conducted not by a single person but by two members of the research team. Even if an interview always is influenced by subjective perceptions, subjectivity in the interpretation of these subjective perspectives could be reduced in this way. The interview guideline prestructured the interviews according to content, thus enabling the comparison or contrast of the statements. It also served as the basis for our team's jointly and continuously developed coding scheme. A common analytical framework helped us in the allocation of cases to the individual types.

We based our analyses on Mayring's (2010) practical research instructions for summarizing or structuring content analysis as well as Kelle and Kluge's (2010) method of typology construction and Kuckartz's (2010a) typological analysis approach. Documentation and thus verifiability was furthermore supported by the fact that the computer-assisted analysis software Atlas.ti was used to perform the analyses. Computer-based analysis is simultaneously considered to be a validity indicator because it facilitates a systematic analysis closely aligned with the data (Wrona 2006).

\section{Internal Validity: Establishing Intersubjective Certainties}

Validity is concerned with the question of operationalization and examines the extent to which data actually measure what should be measured. To ensure this, we

1) examined validity already during the interviews. Participants' statements were summarized, paraphrased, and repeated back to them to ensure mutual understanding (communicative validation, Wrona 2006). In addition, the interview guideline 
served as an "orientation framework and memory aid" (Witzel 1982, 1996) to ensure that all relevant topics were discussed. As the interviews were conducted by two researchers, they were jointly reflected upon immediately afterwards.

2) During the evaluation process, the research team performed the ongoing discursive validation of each analytical step and the ensuing results. These discussions focused both on text interpretation as well as on methodological or theoretical aspects. To ensure that a common understanding of the key analysis dimensions was present from the start, we extensively discussed each individual code and developed a coding guideline with definitions and examples for all categories and subcategories. The hierarchical arrangement of the codes within the category system was also uniformly regulated. The final specifications were the result of the test coding of about one-quarter of the interviews by all members of the research team, which served to determine the practicability of the categories and to uncover and ultimately eliminate ambiguities and misunderstandings in the coding process.

3) Validation also requires guaranteeing the validity of the results. This means that the findings must be empirically supported by the data (Steinke 2007; Wrona 2006). Therefore, in the team we discussed the results of the analyses, the assumptions, interpretations, and particularly the types that were formed based on the data. These discussions served to verify and, if necessary, modify or reject the results. They led, for instance, to several stages of renaming the types until they received their final designation as well as to a reduction in the total number of established types. The patterns that were identified had to occur in a sufficient number of cases, and there had to be an adequate number of references supporting these in the texts. Likewise, "atypical" cases that could not be fully classified into the pattern of a type had to be taken into account and described.

4) In addition to our internal validation by the team, discursive validation was performed as part of a review process by external experts. Our scientific advisory committee should be mentioned first; this committee, composed of national and international experts from fields of science and practice at home and abroad, accompanied the creation of the Youth Report, providing constructive and critical support in the course of several advisory committee meetings. Mostly methodological, but also theoretical suggestions were provided and we were given substantive ideas concerning the qualitative research process. Our results were also validated in independent focus groups with other experts: In a total of six thematic focus group discussions and by written correspondence, the experts were given the opportunity to share their feedback, comments, and questions with respect to the typology. This also helped to increase the plausibility and verifiability of findings.

Although our control of the interpretation within the research team and the validation by scientific discourse does not guarantee "absolute certainty" about the validity of the results and their generalizations, it does lead at least to "intersubjective certainties" (Reichertz 2000, p. 73).

Finally, the practice of triangulation of various studies and results that was applied in the Youth Report also contributed to the validation of our results. The findings of the present qualitative analysis were related to those of the secondary analyses as well as the quantitative survey of young people participating in support services. This led to 
further validation and to a deeper understanding of the results and increased the chances of their generalizability.

\section{External Validity: Generalization of the Results}

Lastly, external validity focuses on the question of whether the research findings are transferable and generalizable.

A central strategy used to generalize the sample results is the sampling procedure (described in Section 2), which ensures that the sample is theoretically representative. In sampling strategies following theoretical considerations, the goal of generalization already exists: Based on these considerations, the deliberate selection of cases aims for the adequate representation of the population on the phenomenological level. This increases the probability that the empirical results can be transferred to the population in general.

The minimal and maximal contrast procedure ensured that a sufficient number of distinct cases were included thus providing broad, comprehensive coverage of the heterogeneity of the transitions. We included as many persons in the sample necessary to reach theoretical saturation. By interviewing 77 people, our qualitative study sample was quite large, which is also conducive for making generalizations. Specifically, when an increasing number of cases are analyzed, then more general conclusions can be drawn from the data (Seawright and Gerring 2008).

Limitations of the single case are overcome by forming types. Cross-case patterns and correlations are revealed that lay claims of validity for all the cases that can be classified in a particular type. Types, therefore, always represent an abstraction and, thereby, a generalization of the characteristics of the single cases.

The results on the typology of transitions to work and coping patterns of young people in Luxembourg described in Section 3 represent a form of abstraction and generalization. The established typology is a theoretical construct that facilitates the classification, interpretation, and generalization of the results. The derived findings are the result of a) theoretical and b) interpretive (inferential) generalization:

a) As theoretical generalization we understand the interpretation of the results with respect to the research questions and the context of the study. The aim of theoretical generalization is to broaden the existing theoretical knowledge (Maxwell and Chmiel 2014). The construction of types thus serves the theoretical generalization of the results of a comparative case analysis. The validity of these generaliziations was proved by verifying, modifying or discarding the inductively obtained findings during the analysis process.

Taking into account the existing theories, we evaluated and interpreted the results in the theoretical context. Results reveal that the transition passages of the interviewees differ from each other with respect to course of and coping with the transition in a way similar to the five transition types reported in Walther and Plug's (2006) typology. Hence, all participants were, according to their transitions to work, initially classified in one of Walther and Plug's (2006) transition types, and we examined whether this classification was realistic and useful for the present study. This revealed, however, that although the transitions of adolescents and young adults in Luxembourg differentiate among each other in a similar way, the reconstructed profiles could not be completely 
classified in their typology. The classification, description, and definition of the types was therefore adapted to the needs of the present study.

Four transition types emerged that allow us to depict the ideal biographical profiles of adolescents and young adults in Luxembourg (Schumacher et al. 2015):

Direct transition: Adolescents and young adults belonging to this type can look back upon a successful and rapid transition. There is only a short period between leaving education and beginning permanent employment. They arrive without encountering problems and detours in their working life; their career paths are straightforward.

Alternative transition: Adolescents and young adults of this type have followed a career that was characterized by various creative detours and stages of "trial and error." They did not achieve their current status by following a direct path, rather through diverse stages of reorientation. The passages are very heterogeneous and are the result of individual choices and creative solutions; in most cases they lead to integration in the labor market.

Transition requiring support: This type category includes adolescents and young adults who are confronted by major difficulties in the transition into employment and therefore require help. Despite investing varying degrees of effort, they have not yet arrived in working life: At the time of interview, almost all participants in this type were either unemployed and had previously, at best, short-term, temporary employment. Therefore, they try to accomplish the transition with outside support. This includes, for example, participation in labor market integration schemes as well as measures such as assisted living or assistance in the form of counseling and support. Failed transition: For some adolescents and young adults, the transition to work is not expected to take place in the foreseeable future. As a result of their precarious and highly problematic overall situation, at the present time their transition must be considered as failed. Not only have these individuals experienced various failures in the transition to work, they also are struggling with multiple problems in the different areas of their lives. They are frequently characterized by dysfunctional family relationships as well as serious personal and interpersonal problems.

We could show the various factors of success, conditions for success, and barriers of the transition to working life based on the characteristics used to define the different types. In addition, we could derive suggestions for the assistance and support needs of each transition type. Based on the theoretical generalization, it is assumed that each case belonging to a certain type has the same or similar attributes even though empirical differences certainly exist between the cases belonging to a type.

b) Moreover, the results should also allow conclusions to be drawn about the target population, the youth of the country of Luxembourg. In order to transfer the singlecase results to yet unstudied cases or to parts of the population, they must be generalized. This cannot be done based on statistical rules as is the case in quantitative studies, but must be obtained argumentatively; Lewis and Ritchie (2003) refer to this as "inferential generalization". ${ }^{3}$ On the interpretive level,

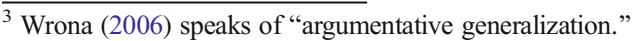


overall findings concerning the transitions of young people in general were derived from the analysis of the interviews. Thus, familial support was identified as an important influential factor. Regarding transition, analyzing all the interviews made clear the large role played by familial resources and coping support services. This could be demonstrated for those adolescents and young adults who successfully shaped their transitions themselves as well as for the group of adolescents and young adults whose transitions were regarded as problematic or, at the time of survey, failed.

We now assume that this finding is not only restricted to the 77 interviewed adolescents and young adults but applies to all young people in an identical or similar manner. This cannot be derived directly from the empirical data, but is an interpretation based on the results. The continuously recurring patterns and regularities within each type as well as the differences between the types strongly suggest that our study identified regularly occurring phenomena that is valid beyond the present sample. This assumption of "moderatum generalization (Williams 2002) in the findings "can be seen to be instances of a broader recognizable set of features" (Williams 2002, p. 131), and is the most common form of generalization in interpretive research.

\section{General Conclusion: Opportunities and Complications in Generalization}

Aggregating single-case based data and the generalizability and transferability of these findings is surrounded by preconditions. Not every survey allows the derivation of universal statements, but the degree of generalizability is closely related to the research question, the methodological design, and the methodological approach. In the present study, our research design as well as our systematic approach guided by scientific rules contributed significantly to improving the generalizability of the findings.

Overall, the findings of the study certainly do not allow us to make universally valid assertions; however, through the identification of key factors influencing the transition of young people as well as the similarities and differences between the types, they do allow moderate generalizations to be made as described above. Although they neither provide exact prognoses nor numerical generalizations (allowing, e.g., the calculation of probabilities for success or failure of transitions), they do provide a theoretical generalization (Seale 1999) by allowing us to make general conclusions about young peoples' experienced course of and coping with their transition.

The insights gained in this study tie in with, empirically reflect, and add to the existing theoretical knowledge in the context of transitions to working life. Thus, they can also be considered as valid in a functional sense (Scholz and Tietje 2002). Our results can be linked to existing research, and they contribute to a more comprehensive understanding of the individual course of and coping with transitions and their related challenges and difficulties. This study also provides explanations for more and less successful transitions and generates knowledge on key factors such as familial support, education, migration, self-efficacy, or value orientations that affect young people's transitions from school to the labor market. This knowledge is not only useful for the scientific community, it also benefits policy-makers and practitioners, for example, in the creation and implementation of labor market integration schemes targeting young people. 
In addition to the possibilities of data aggregation and generalization outlined above, our in-depth look provided additional insights into the conditions for success and the encountered obstacles with respect to the transition period. Whereas the transition types delineated here provide generalizable explanations beyond the single case, additional factors that might affect transition were revealed by the atypical cases that could not be categorized according to the pattern of a particular type. Here, we speak of "critical moments," that is, critical life events such as dropping out of school, unemployment, death or illness of a parent, separations, and other breaks that led some of our interviewed young people to change their life plans. Although these specific cases cannot be generalized, due to their specific characteristics they could add additional, previously unconsidered insights on transitions.

\section{Compliance with Ethical Standards}

Funding This study was funded by the Ministry of Education, Children and Youth Luxembourg. The funding is based on a cooperation aggreement between the ministry in charge of youth policy and the University of Luxembourg.

Conflict of Interest The first author declares that he has no conflict of interest. The second author declares that he has no conflict of interest.

Ethical Approval All procedures performed in studies involving human participants were in accordance with the ethical standards of the institutional and national research committee and with the 1964 Helsinki declaration and its later amendments or comparable ethical standards.

Informed Consent Informed consent was obtained from all individual participants included in the study.

\section{References}

Bohnsack, R. (2003). Rekonstruktive Sozialforschung. Einführung in qualitative Methoden (5. Aufl.)[reconstructive social research. Introduction to qualitative methods, 5th ed.]. Opladen: Leske + Budrich.

Chowdhury, M. F. (2015). Coding, sorting and sifting of qualitative data analysis: debates and discussion. Quality \& Quantity, 49(3), 1135-1143.

Cohen, L., Manion, L., \& Morrison, K. (2007). Research methods in education. New York: Taylor \& Francis. Flick, U. (2002). Qualitative Sozialforschung: Eine Einführung. Reinbek: Rowohlt.

Flick, U. (2008). Triangulation in der qualitativen Forschung [triangulation in qualitative research]. In U. Flick, E. von Kardorff, \& I. Steinke (Eds.), Qualitative Forschung: Ein Handbuch (pp. 27-50). Reinbek: Rowohlt.

Glaser, B. G., \& Strauss, A. L. (1998). Grounded theory. Strategien qualitativer Forschung [grounded theory. Strategies of qualitative research]. Bern u.a: Huber.

Guest, G., Bunce, A., \& Johnson, L. (2006). How many interviews are enough?: an experiment with data saturation and variability. Field Methods, 18(1), 59-82.

Havighurst, R. J. (1972). Developmental tasks and education. New York: Longman.

Helfferich, C. (2011). Die Qualität qualitativer Daten: manual für die Durchführung qualitativer interviews [the quality of qualitative data: manual for conducting qualitative interviews]. Wiesbaden: Springer VS.

Hurrelmann, K. (2009). Lebensphase Jugend. Eine Einführung in die sozialwissenschaftliche Jugendforschung [Lifestage adolescence. An introduction to social youth research]. Weinheim: Juventa.

Jacob, R., Heinz, A., \& Décieux, J. P. (2013). Umfrage: Einführung in die Methoden der Umfrageforschung [introduction to methods of survey research]. München: Oldenbourg Wissenschaftsverlag. 
Kelle, U., \& Kluge, S. (2010). Vom Einzelfall zum Typus. Fallvergleich und Fallkontrastierung in der qualitativen Sozialforschung (2. überarb. Aufl.) [from single case to classification type. Case comparison and case contrast in qualitative social research, 2nd rev. ed.]. Wiesbaden: VS Verl. für Sozialwissenschaften.

Kluge, S. (2000). Empirisch begründete Typenbildung in der qualitativen Sozialforschung [Empirically grounded construction of types and typologies in qualitative social research]. In: Forum Qualitative Sozialforschung / Forum: Qualitative Social Research [Online Journal], 1 (1). http://nbn-resolving. de/urn:nbn:de:0114-fqs000114.

Kohli, M. (1985). Die Institutionalisierung des Lebenslaufs. Historische Befunde und theoretische Argumente [The institutionalization of the life course. Historical findings and theoretical arguments]. In: Kölner Zeitschrift für Soziologie und Sozialpsychologie 37, 1, S. 1-29.

Kohli, M. (1988). Normalbiographie und Individualität [The normal biography and individuality]. In: H.-G. Brose \& B. Hildenbrand (Hrsg.), Vom Ende des Individuums zur Individualität ohne Ende. Opladen: Leske + Budrich.

Kohli, M. (2000). Arbeit im Lebenslauf: Alte und neue Paradoxien [Work in the life course: Old and new paradoxes]. In: J. Kocka \& C. Offe (Hrsg.), Geschichte und Zukunft der Arbeit. Frankfurt: Campus. 362382.

Kuckartz, U. (2010a). Typenbildung [Type formation]. In: K. Mruck \& G. Mey (Hrsg.), Handbuch qualitative Forschung in der Psychologie. Wiesbaden: VS Verlag für Sozialwissenschaften. 553-568.

Kuckartz, U. (2010b). Einführung in die computergestützte analyse qualitativer Daten [introduction to computer analysis of qualitative data]. Wiesbaden: VS Verlag für Sozialwissenschaften.

Lewis, J., \& Ritchie, J. (2003). Generalising from qualitative research. In J. Ritchie \& J. Lewis (Eds.), Qualitative research practice: a guide for social science students and researchers (pp. 263-286). London: Sage.

Marshall, B., Cardon, P., Poddar, A., \& Fontenot, R. (2013). Does sample size matter in qualitative research?: a review of qualitative interviews in IS research. Journal of Computer Information Systems, 54(1), 11-22.

Mason, M. (2010). Sample size and saturation in $\mathrm{PhD}$ studies using qualitative interviews [63 paragraphs]. Forum Qualitative Sozialforschung / Forum: Qualitative Social Research, 11(3), Art. 8 .http://nbnresolving.de/urn:nbn:de:0114-fqs100387

Maxwell, J. A., \& Chmiel, M. (2014). Generalization in and from qualitative analysis. In U. Flick (Ed.), The SAGE handbook of qualitative data analysis (pp. 540-553). London: Sage.

Mayring, P. (2002). Einführung in die qualitative Sozialforschung. Eine Anleitung zu qualitativem Denken (5. überarb. Aufl.) [introduction to qualitative social research, 5th rev. ed.]. Weinheim: Beltz.

Mayring, P. (2007). Generalisierung in qualitativer Forschung [23 Absätze] [Generalization in qualitative research]. Forum Qualitative Sozialforschung / Forum: Qualitative Social Research, 8(3), Art. 26 .http://nbn-resolving.de/urn:nbn:de:0114-fqs0703262

Mayring, P. (2010). Qualitative Inhaltsanalyse. Grundlagen und Techniken (11. Auflage) [qualitative content analysis. Foundations and techniques, 11th ed.]. Weinheim: Beltz.

Mruck, K., \& Mey, G. (2000). Qualitative Sozialforschung in Deutschland [49 Absätze] [qualitative social research in Germany]. Forum Qualitative Sozialforschung / Forum: Qualitative Social Research, 1(1), Art. 4 .http://nbn-resolving.de/urn:nbn:de:0114-fqs000148

Przyborski, A., \& Wohlrab-Sahr, M. (2010). Qualitative Sozialforschung: ein Arbeitsbuch [qualitative social research: a workbook]. München: Oldenbourg.

Rahn, P. (2005). Übergang zur Erwerbstätigkeit: Bewältigungsstrategien in benachteiligten Lebenslagen [Transition to employment: Coping strategies in disadvantaged situations]. Wiesbaden: VS Verl. für Sozialwissenschaften.

Reichertz, J. (2000). Zur Gültigkeit von qualitativer Sozialforschung [76 Absätze] [on the problem of validity of qualitative research]. Forum Qualitative Sozialforschung / Forum: Qualitative Social Research, 1(2), Art. 32 .http://nbn-resolving.de/urn:nbn:de:0114-fqs0002324

Reinders, H. (2003). Jugendtypen: Ansätze zu einer Differentiellen Theorie der Adoleszenz [adolescent types. Approaches to a differential theory of adolescence]. Opladen: Leske + Budrich.

Sandelowski, M. (1995). Sample size in qualitative research. Research in Nursing \& Health, 18(2), $179-183$.

Scholz, R. W., \& Tietje, O. (2002). Embedded case study methods: integrating quantitative and qualitative knowledge. New York: SAGE Publications.

Schumacher, A.; Haas, C.; Weis, D. \& Heinen, A. (2015). Übergänge vom Bildungssystem in die Arbeitswelt [Transitions from the educational system to the working world]. In H. Willems (Hrsg.), Übergänge vom Jugend- ins Erwachsenenalter: Verläufe, Perspektiven, Herausforderungen. Luxemburg. 61-162.

Schütze, F. (1983). Biographieforschung und narratives interview [biographical research and narrative interview]. Neue Praxis, 13(3), 283-293. 
Seale, C. (1999). The quality of qualitative research. London: Sage.

Seawright, J., \& Gerring, J. (2008). Case selection techniques in case study research - a menu of qualitative and quantitative options. Political Research Quarterly, 61(2), 294-308.

Steinke, I. (2007). Qualitätssicherung in der qualitativen Forschung [Quality control in qualitative research]. In: U. Kuckartz, H. Grunenberg \& T. Dresing (Hrsg.), Qualitative Datenanalyse: computergestützt. Wiesbaden: VS Verlag für Sozialwissenschaften 176-187.

Steinke, I. (2008). Gütekriterien qualitativer Forschung [Quality criteria of qualitative research]. In U. Flick, E. von Kardorff \& I. Steinke (Hrsg.), Qualitative Forschung: Ein Handbuch (6. Aufl.). Reinbek: Rowohlt. 319-332.

Uhlendorff, U. (2010): Typenbildende Verfahren [Methods of typology construction]. In: K. Bock, I. Miethe \& B. Ritter (Hrsg.), Handbuch qualitative Methoden in der Sozialen Arbeit. Opladen: Barbara Budrich. 314-324.

Walther, A., \& Plug, W. (2006). Transitions from school to work in Europe: Destandardization and policy trends. New Directions for Child \& Adolescent Development, 113, 77-90.

Willems, H. (Hrsg.) (2015). Übergänge vom Jugend- ins Erwachsenenalter: Verläufe, Perspektiven, Herausforderungen [Transitions from adolescence to adulthood: Profiles, perspectives, challenges]. Luxemburg.

Willems, H., Schumacher, A. \& Heinen, A. (2015a). Die Konzeption des luxemburgischen Jugendberichtes [The conception of the Luxembourg Youth Report]. In H. Willems (Hrsg.), Übergänge vom Jugend-ins Erwachsenenalter: Verläufe, Perspektiven, Herausforderungen. Luxemburg. 33-48.

Willems, H., Weis, D., Biewers S., Haas, C., Heinen, A., Joachim, P., \& Meyers, C., et al. (2015b). The transition from youth into adulthood: processes, perspectives, challenges. In Ministère de l'Éducation nationale, de l'Enfance et de la Jeunesse \& University of Luxembourg (Eds.), The transition from youth into adulthood: Summary of the national report on the situation of young people in Luxembourg, pp. 1964.

Williams, M. (2002). Generalization in interpretive research. In T. May (Hrsg.), Qualitative research in action (pp. 125-143). London: Sage.

Witzel, A. (1982). Verfahren der qualitativen Sozialforschung. Überblick und Alternativen [methods of qualitative social research. Overview and alternatives]. Frankfurt a.M.: Campus.

Witzel, A. (1996). Auswertung problemzentrierter Interviews. Grundlagen und Erfahrungen [Analysis of problem-centered interviews. Basics and experiences]. In: R. Strobl \& A. Böttger (Hrsg.), Wahre Geschichten? Zur Theorie und Praxis qualitativer Interviews. Baden Baden: Nomos, 49-76.

Witzel, A. (2000). Das problemzentrierte Interview [The problem-centered interview]. In: Forum Qualitative Sozialforschung / Forum: Qualitative Social Research [Online Journal], 1 (1). www.qualitativeresearch.net/index.php/fqs/article/view/1132/2520.

Wrona, T. (2006). Fortschritts- und Gütekriterien im Rahmen qualitativer Sozialforschung [Progress and quality criteria as part of qualitative social research]. In: S. Zelewski (Hrsg.), Fortschritt in den Wirtschaftswissenschaften. Wissenschaftstheoretische Grundlagen und exemplarische Anwendungen. Wiesbaden: Gabler 189-216.

Daniel Weis is working as research associate at the Research Unit INSIDE - Integrative research on social and individual development, University of Luxembourg, Esch-Belval, Luxembourg.

Helmut Willems is professor for general sociology and youth sociology at the Research Unit INSIDE Integrative research on social and individual development, University of Luxembourg, Esch-Belval, Luxembourg. 